\title{
Planning and diagnostic nursing strategy in the clinical management of the patient with hyperthroidism
}

\begin{abstract}
Hyperthyroidism is a common disease that affects $0.8 \%$ of the population in Europe. It occurs when the thyroid gland produces more thyroid hormones than your body needs. There are several types of treatment, such as antithyroid drugs, treatment with radioactive iodine (131I) and finally surgery, in addition to these treatments, reference is made to a good hygienic-dietary orientation.
\end{abstract}

Objective: to assess from the nursing field the safest and most effective type of hyperthyroidism treatment, including the risk factors to take into account when carrying out these.

Methodology: systematic searches were carried out in bibliographic sources of trials and articles published between 2015 and 2021. Including studies that contained data on risk factors for hyperthyroidism.

Results: of 426 related articles found, 13 met the inclusion criteria. Total thyroidectomy surgery induced a $26 \%$ therapeutic failure rate and $95 \%$ radioactive iodine treatment compared to the $19.1 \%$ therapeutic failure in antithyroid drug treatment.

Conclusion: Despite the verification of the efficacy of all existing hyperthyroidism treatments, antithyroid drugs have greater efficacy and safety than the rest of the treatments studied, in relation to the time and rate of remission. On the other hand, risk factors such as tobacco and female sex are evidenced, which are negative factors when carrying out treatment for hyperthyroidism.

Keywords: graves' disease, antithyroid drugs, radioactive iodine therapy, methimazole, propylthiouracil, thyroid gland
Volume 7 Issue I - 2022

\begin{abstract}
Astasio Picado Álvaro
PhD Nursing and Physiotherapy Department, University of Castilla-La Mancha, Faculty of Health Sciences, Talavera de la Reina, Toledo, Spain

\section{Correspondence: Álvaro Astasio Picado Federico García Lorca, University of Castilla-La Mancha, Faculty of Health Sciences, Talavera de la Reina,Toledo, 21 Plasencia (10600-Cáceres) Spain, Email alvaro.astasio@gmail.com}

Received: December 27, 2021 | Published: January II, 2022

\section{Introduction}

Hyperthyroidism is an endocrine disease that affects the thyroid gland, hyperproducing thyroid hormones, which can lead to serious consequences and considerably decrease the quality of life if it is not treated properly. This disease has a prevalence of $0.8 \%$ in Europe and is also more frequent in women and increases with age. ${ }^{1}$

There are no modifiable factors to prevent this disease, so it is important to thoroughly study pharmacological and nonpharmacological treatment, as well as other activities that help restore the quality of life and health of patients suffering from this pathology. ${ }^{1,2}$

The treatment of this disease is largely based on the union of pharmacological and non-pharmacological treatments such as diet or lifestyle and, for example, the administration of radioactive iodine. ${ }^{3}$

The active treatments for the control of hyperthyroidism are gathered in 3, the administration of radioactive iodine, some antithyroid drugs and finally, in case the previous ones do not work, the thyroid surgery (thyroidectomy " $\mathrm{TT}^{\prime \prime}$ ). ${ }^{4}$

Before being diagnosed with hyperthyroidism, many patients were diagnosed with hypothyroidism, so it should be noted that certain treatments of the opposite disease can trigger hyperthyroidism and vice versa. $^{3}$

From the nursing point of view, when carrying out a good plan for the prevention of hyperthyroidism, we find the difficulty that this disease presents as it is so limited, since it is described as adisease where hormonal alterations, in most cases respond to diseases in which self-care does not influence.

On the other hand, a large number of these patients with thyroid nodules do not show known risk factors, which makes it impossible to prevent the disease, due to lack of information.

This is why, from the field of nursing, we want to investigate this disease, which from the first instance is known that it is impossible to prevent it, therefore, we will proceed to look for scientific evidence on the treatments and factors that harm these, in order to highlight the important points of the disease and mark the key concepts to take into account when treating hyperthyroid patients.

Hyperthyroidism is a disease that depends on the thyroid gland, it is shaped like a butterfly and is usually located in the front part of the neck, under the larynx, it is responsible for forming thyroid hormones, carrying these to the bloodstream and leading to all body tissues. These thyroid hormones help the body use energy, maintain body temperature, and help the brain, heart, and other organs function normally. ${ }^{5}$

An excessive increase in these hormones is called thyrotoxicosis. ${ }^{6}$

Hyperthyroidism therefore refers to any condition in which there is an excessive amount of thyroid hormone in the body. That is, the thyroid gland is hyper-active. When there is an excess of this hormone, all the functions of the body tend to accelerate, so that some of the symptoms of hyperthyroidism can be nervousness, increased 
sweating, irritability, difficulty in sleeping and concentrating, palpitations, tremors in the hands, anxiety, thinning of the skin, the hair becomes fine and brittle, in women it can be reflected with lighter flows and less frequent menstrual periods, and weakness in the muscles, especially in the arms and thighs. ${ }^{1,6}$

Hyperthyroidism can present in several ways, depending on the cause:

Diffuse toxic goiter or graves-basedow disease: constitutes the formmore usual hyperthyroidism, being (70\%) of all cases. It can appear at any age, being most common between the third and fourth decade of life. This disease is characterized by hyperthyroidism, diffuse and elastic goiter, and among others, ophthalmopathy, dermopathy, thyroid acropachy and onycholysis. It is located within autoimmune diseases, in which thyrotropin receptor antibodies stimulate the thyrotropin receptor (TSH), and increase the production of thyroid hormone. ${ }^{1,7}$

Toxic thyroid adenoma: this is not an autoimmune disease, it is due to a mutation of the thyrotropin receptor gene. It is a thyroid nodule that acts autonomously and secretes a large amount of thyroid hormones (T3) and (T4). It is a cause of hyperthyroidism with suppressed levels of thyroid stimulating hormone (TSH). They make up $2-10 \%$ of all hyperthyroidism cases.

Toxic multinodular goiter: it is also known as Plummer's disease, it contains a large number of nodules that act autonomously, causing hyperthyroidism. These nodules act independently of thyroid stimulating hormone (TSH), they are usually benign, although inactive thyroid nodules in the same goiter can be malignant. It is more common in elderly patients. ${ }^{6,7}$

Thyrothropin-producing hypophyseal adenoma: characterized by the presence of a pituitary mass associated with high levels of circulating free thyroid hormones, together with levels of thyroidstimulating hormone (TSH) that vary between high and normal levels, and the absence of thyroid-stimulating hormone (TSH). (TSH) response to TRH stimulation and T3 suppression test. It usually manifests with signs and symptoms of mild to moderate hyperthyroidism. Goiter is the most common symptom.

Iodine-induced hyperthyroidism, amiodarona: the exhibition of thebody to high amounts of iodine can lead to alterations in thyroid function, producing in case of an excessive increase, hyperthyroidism. Sources of iodine to consider include drugs, dietary supplements, antiseptic solutions, or iodinated contrasts that are used in imaging tests. It presents with a discreet goiter, unless previously presented. ${ }^{6}$

\section{Epidemiology}

The prevalence of hyperthyroidism in the general population varies between 0.3 and $1 \%$, with the prevalence of hyperthyroidism being $0.8 \%$ in Europe and $1.3 \%$ in the US It is more frequent in women and increases with age. affecting $2 \%$ of women and $0.2 \%$ of men over 60 years of age. In geriatric population these markers grow reaching $4.6 \%$ due to subclinical hyperthyroidism. ${ }^{5,6}$

\section{Evolution of the disease}

In general, patients with hyperthyroidism and under treatment usually have an oscillating evolution with remissions if not treated well, as for example in Graves-Basedow disease. ${ }^{6,8}$

Therefore, if no good treatment is carried out for any type of hyperthyroidism, the disease can lead to a thyrotoxic crisis. Acute disease situation characterized by dehydration, severe cardiac tachycardia or arrhythmia, heart failure, drowsiness, and impaired consciousness. $^{8}$

It can be fatal, so urgent treatment is required. ${ }^{8}$

Hyperthyroidism is mostly an easy disease to control if good adherence to medical guidelines and proper treatment are carried out. ${ }^{8}$

\section{Etiology}

The main causes that can increase the production levels of thyroid hormones and thus produce hyperthyroidism are: ${ }^{9}$

I. Graves' disease is the most common form of hyperthyroidism, accounting for $80 \%$. It is an autoimmune disease, the eyes can be seen larger since the upper eyelids are raised and some patients suffer from inflammation in the front part of the neck, due to the enlargement of the thyroid gland (goiter). This disease is caused by antibodies in the blood, which stimulate the thyroid gland to grow and secrete excess thyroid hormone. This disease is frequent in families and more in young women. ${ }^{9}$

II. Thyroiditis is an inflammation of the thyroid due to viral infections, some medications or after pregnancy. This causes stored thyroid hormone to leak out of the thyroid gland.

III. Increase in iodine levels. Iodine is essential for the production of thyroid hormones, it is not produced by the body naturally so it is obtained mainly from foods such as salt, seafood and fish, including tuna or salmon. An iodine increase from the abuse of foods that contain it can increase the activity of the thyroid gland and thus produce hyperthyroidism.

IV. Benign tumors of the pituitary or thyroid gland, which cause the secretion of hormones from other glands, such as the thyroid, to be deregulated. Toxic thyroid adenoma is not an autoimmune disease, this disease is due to a mutation of the receptor gene for thyrotropin (thyroid stimulating hormone, abbreviated "TSH ", produced by the anterior pituitary gland that regulates the production of hormones by the gland thyroid), it is a single thyroid nodule, that is, an adenoma that occurs in several stages. This disease is treated with surgery and previous antithyroid treatment.

V. Tumors of the testicles or ovaries, which also deregulate the production of thyroid hormones. This cause is the least common of hyperthyroidism. ${ }^{8-12}$

\section{Risk factor's}

- Women: the prevalence of alterations in thyroid function in women is high $(3 / 1,000)$, many of these conditions occur at childbearing age and in many cases pregnancy can be associated with the disease.

- Over 60 years: there is a decrease in the secretion of thyroid hormones. TSH increases with age and T4 metabolism decreases, they suffer from systemic non-thyroid diseases and consume certain medications, such as phenytoin, which influence the time of thyroid metabolism and physiology.

- Pregnancy or childbirth in the last 6 months: during gestation there are important physiological changes that affect maternal parameters of thyroid function, such as a decrease in TSH (Thyroid Stimulating Hormone) and consequent increase in HCG (Human Chorionic Gonadotropin) the first trimester.

I. Thyroid surgery or thyroid problem, such as goiter.

II. Family history of thyroid disease 
III. Pernicious anemia, in which the body cannot make enough healthy red blood cells because it does not have enough vitamin B12

IV. People with type 1 diabetes mellitus or primary adrenal insufficiency (hormonal disorder)

V. High iodine intake, when eating large amounts of food or using medications or supplements with iodine. ${ }^{13-15}$

The main objective of this work is to demonstrate the most effective and safest type of treatment for hyperthyroidism, and the external factors to take into account from the nursing field.

\section{Material and methods}

The elaboration of this work was carried out by means of a bibliographic search in scientific databases of the articles comprised between January 2015 and June 2021, in order to carry out a narrative review of the literature.

For the selection of the scientific articles on which this narrative review is based, the following criteria have been carried out:

\section{Inclusion criteria:}

I. Research articles were selected in English and Spanish.

II. Articles focused on the pharmacological and nonpharmacological treatment of hyperthyroidism.

III. Articles related to the nursing performance with hyperthyroid patients.

IV. Articles published in the last 5 years.

\section{Exclusion criteria}

I. Articles that are not related to the pharmacological and nonpharmacological treatment of hyperthyroid patients.

II. Articles that do not mention at least 3 terms in the search string.

III. Articles whose year of publication was prior to 2015 included.

Studies will be identified by computer searches in bibliographic databases and in article reference lists, from January 2015 to February 2021. The selected information sources were in English and Spanish.
The following databases were used: Pubmed, Scielo, Google Scholar, Dialnet and Elsevier. The first search was conducted on November $11,2020$.

In addition to these sources of information, information obtained through the analysis of the registry of trials, protocols and websites of official institutions was consulted.

To carry out the internet search, keywords were used: "Treatment (Treatment)"; "(Thyroid Gland) thyroid gland"; "(Hyperthyroidism) hyperthyroidism", "Iodine (radioiodine)", "thyrotoxicosis (thyrotoxicosis)","Graves disease", "(Antithyroid drugs) antithyroid drugs".

To carry out the search string, the Boolean markers (AND), (OR) AND (NOT) have been used, as follows: Treatment " AND" Thyroid gland " OR" Hyperthyroidism, " AND" Radiodine " OR" thyrotoxicosis " OR" Graves 'disease "AND" atithyroid drugs.

To carry out the selection of these studies, a first bibliographic search was carried out, from which 426 articles were obtained. After applying the inclusion and exclusion criteria, a total of 142 articles were identified. Subsequently, after eliminating duplicate and irrelevant articles both for their abstract and for their title, 45 articles were selected. Of these articles, 32 were excluded because they did not provide relevant information of interest, so that the studies selected for this review were 13 articles.

\section{Pico question:}

P: Patients with hyperthyroidism.

I: Radioactive iodine treatment and risk factors for hyperthyroidism.

C: Treatment with antithyroid drugs.

O: Optimal type of treatment for the cure of hyperthyroidism, safer and more effective.

\section{Results}

Below is a Table 1 that shows the search strategy used to select the articles:

To carry out the narrative review, 13 articles were used that met the unified inclusion criteria in the methodology.

Table I Flowchart of the selected studies

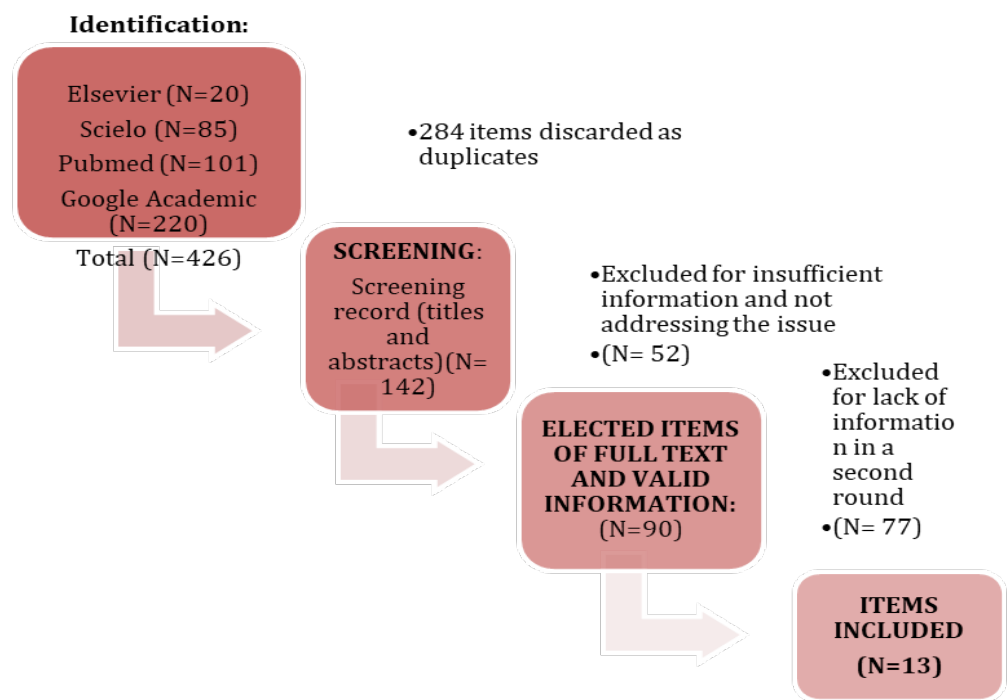




\section{Discussion}

As regards the discussion, it has been tried to reflect the trajectory of the aforementioned bibliography, highlighting what is important in question.

In the first place, we will begin by explaining what is relevant to treatment with total thyroidectomy (TT), with radioactive iodine (131I), followed by treatment with ADT and the comparison that is made of the latter two to stop at the question to be discussed. On the other hand, it has been decided to emphasize epidemiology as an area to be investigated.

From the previous evidence it can be seen that regarding treatment with (TT), it is intended to demonstrate its efficacy, but it reflects how $26.9 \%$ of the patients studied have shown a therapeutic failure, which leads us to compare this treatment with the others studied, and it is reflected that despite its high effectiveness, the failure threshold is much higher than in the treatments with (ADT) and (131I), obtaining these as described by the authors Azizi F, et Malboosbaf R. in one and Zhao Lina et al. ${ }^{1}$ in another article respectively summarized in the results, with $19.1 \%$ failure in terms of antithyroid drugs and $22.3 \%$ in treatment with radioactive iodine (131I). ${ }^{18,24,27}$

For treatment with radioactive iodine (131I), each investigation has decided to take a variable as the field of investigation in relation to hyperthyroidism, and as each of these has established percentages making relevance to the effects of the treatments, that is where it is generates our task, in observing which of these could give the best solution to the need in question..$^{20,24,26}$

Now, in this demonstration we find 6 articles, in the first place, we will stick to highlighting the results in common, where their effectiveness is exposed since only $22.3 \%$ are shown that they have not achieved the success of the treatment causing a hypofunction of the thyroid gland. ${ }^{24}$

In relation to people exposed to iodine, it is intended to demonstrate how it causes the risk of suffering from cancer and only shows a greater risk of Non-Hodgkin's Lymphoma (NHL), due to the high percentage of therapeutic failure, a study is carried out in which show that stimulation with the recombinant human thyrotropin hormone (rhTSH) improves the absorption of (131I), increasing the percentage of efficacy, although there is still a $12.5 \%$ therapeutic failure..$^{21,22}$

In addition, it is evidenced that the treatment with (131I) is a trigger for another pathology such as overweight because this therapy is associated with an additional increase of $0.6 \mathrm{KG}$, compared to treatment with (ADT) alone..$^{23}$

Regarding the mortality related to this therapy of (131I), the probability is high $(95 \%)$, but this is not related to cancer, but due to all the causes themselves. ${ }^{26}$

On the other hand, regarding Toxic Multinodular Goiter (BMN) and Toxic Autonomous Nodule (NAT), administering a lower dose of iodine is an optimal treatment to control the disease, highlighting the variable that the male sex and a previous treatment ADT are negative factors when using Radioactive Iodine (131I) treatment. ${ }^{20}$

At the same time, it is demonstrated that in smoking patients with Graves-Basedow disease, it was necessary to use a second dose of treatment with respect to the rest of the patients, therefore, tobacco decreased the effectiveness of the therapy. ${ }^{25}$

Now, based on these evidences, the results of the investigations in relation to the treatment of antithyroid drugs (ADT), specifically
Metimazole, will continue to be presented, since it is the most mentioned and of first choice.

Linked to this are two evidences of the efficacy and safety of this last treatment, sharing the fact that the frequency of clinical signs decreases, assuming a lower rate of complications and that these can be corrected with a dose adjustment. Thus demonstrating its efficacy and safety, which is also evidenced in treatment with radioactive iodine (131I), which is discussed at the same time that a decrease in the dose would achieve an improvement in the efficacy of radioactive iodine treatment. ${ }^{19,20.27}$

Within this framework we find new evidence in which it is exposed that a minimum maintenance dose therapy with antithyroid drugs (ADT) with a duration of more than six months, also related to a high $\mathrm{T} 3$ and fT4 at the time it is withdrawn these drugs are predictors of disease relapse. ${ }^{29}$

Referring to the first article included in the results, it has been seen to be especially important to reflect the comparisons that have been studied of treatment with (ADT) and with (131I). It is for this reason that it was decided to search bibliographically for something else that evidences it apart from the tables that have been demonstrating it, so that a greater difference is manifested. Therefore, in the research that compares these two treatments, it is evident on the one hand that both have the quality of life in relation to health in a similar way, but an important difference is exposed, and that is that in the treatment with Radioactive Iodine (131I) only 5\% achieved full efficacy of this, compared with $95 \%$ efficacy of antithyroid drugs (ADT). ${ }^{17}$

After what has been mentioned above, we find an article where we want to emphasize the results that show the risk factors to take into account when suffering from any type of hyperthyroidism and to choose the most appropriate type of treatment, such as are: female sex, Hypertension (HTN) and Diabetes mellitus, since it is shown that these factors are predictors of the malpractice of hyperthyroidism. ${ }^{28}$

Despite all the information collected and presented in this work, it is realized that, despite the studies found, many variables of hyperthyroidism treatments and risk factors to be investigated are missing, since, if these were carried out, the subsequent Research papers would be more enriching and therefore would further increase their validity.

\section{Conclusion}

The conclusions reached in relation to the initially set objectives are detailed below:

I. Examine the risk factors external to the patient predisposing to a poor prognosis of the disease: among the factors external to the patient that may be predisposing to poor treatment of hyperthyroidism, nursing professionals should take into account that tobacco consumption, which reduces the efficacy and effectiveness of radioactive iodine (131I) treatment, being It is advisable to avoid it, although today it is not a contraindication to undergo the treatment.

II. Determine the safe and effective type of hyperthyroidism treatment: the treatment of choice as investigated, it can be said that it will be methimazole, this being an antithyroid drug (ADT) of high efficacy and safety, and because compared to (131I) and therapy with (TT), It has fewer adverse effects and the practice of this will be considered safe in a higher percentage than treatment with Radioactive Iodine (131I). 


\section{Acknowledgments}

None.

\section{References}

1. Hyperthyroidism. Merck Manual Professional Version. 2018

2. Bethesda (MD): Biblioteca Nacional de Medicina (EE.UU.) Hipertiroidismo (Hyperthyroidism). Medline Plus en español. 2019.

3. Paciente adulto ingresado en las unidades de hospitalización con diagnóstico de hipertiroidismo. Hospital Universitario Ramón y Cajal. $2005 ; 2-9$.

4. L Zhao, W Zhang, Y Xin. Predicción de losresultados clínicos en el tratamiento personalizado con yodo radiactivo de laenfermedadde Graves. Revista Españolade Medicina Nucleare Imagen Molecular. 2018;37(6):359-353.

5. P Taylor, D Albrecht, A Scholz. Epidemiología global Delhi pertiroidismoehipotiroidismo. IntraMed. 2020;14(5):301-331.

6. C Claret Torrents. Etiología, clínica y diagnóstico del hipertiroidismo Manualde patología tiroidea. 2018;1:15-18.

7. A Albarrán,V Andia,P Sánchez. Hyperthyroidism. Concept. Classification. Description of principal types: Pathogenesis, clinical and diagnostic. Thyrotoxic crisis Subclinical hyperthyroidism Treatment Remissioncriteria Medicine. 2008;10:914-921.

8. Jara Albarrán A, Andía Melero V, Sánchez García-Cervigón P Hipertiroidismo. Concepto. Clasificación. Descripción de los principal estipos: patogenia, clínicay diagnóstico. Crisistirotóxica. Hipertiroidism o subclínico Tratamiento. Criterios deremisión. Serviciode Endocrinologíay Nutrición. Hospital General Universitario Gregorio Marañón. 2008;10(14):914-921.

9. Iñahuazo N, Fernando D. Descripción y análisis de signos y síntomas en pacientes con diversos tipos de hipertiroidismo y modalidades de tratamiento practicados en el Servicio de Endocrinología del Hospital Eugenio Espejo entre enero de 2015 a diciembre del 20. Universidad Católica Del Ecuador. 2020.

10. Young P, Finn B C, Bruetman J E. La enfermedad de Graves, signosys íntomas. An Med Interna. 2007;24(10):505508.

11. Rodríguez Ramos JF, Boffill Corrales AM, Rodríguez Soria LA. Factores deriesgo de las enfermedades tiroideas. Hospital del Seguro Social Ambato Nutr Hosp. 2016;20(5).

12. Frías López MC, Tárraga López PJ, Rodríguez Montes JA, et al Hipotiroidism osubclínic oy factores deriesgo cardiovascular. Rev Ciencias Médicas. 2016;20(5).

13. Mongue Montero MA. Patología tiroidea en eladulto mayor. Rev médica de Costa Rica y centro América. 2009;66(589):245-250.

14. Infante Amorós A, Turcios Tristá SA. Hipertiroidismo. Rev Cubana Endocrinología. 2012;23(3).

15. Tamayo P, García P, Martín E, et al. Tratamiento con radioyodo dela patología tiroidea. Rev ORL. 2011;11(3):305-327.
16. M Toni, J Pineda, E Anda, et al. Hipertiroidismo (Hyperthyroid). Medicine - Programa de Formación Médica Continuada Acreditado. Dialnet. 2016;12(13):731-741.

17. Ma C, Xie J, Wang H, et al. Radio iodine therapy versus antithyroid medications for Graves' disease. Cochrane Database of Systematic Reviews. 2016;2.

18. Pardo M Lourdes. Resulta dos delatiroi dectomía total en eltratam ento delhi pertiroidismo. Rev Otorrinolaringólogo Cir Cabeza Cuello. 2020;80(1):39-47.

19. Alvira J, Galván G, Ordoñez J. Eficacia y Seguridad del metamizol en eltratamiento del hipertiroidismo por enfermedad de Graves en menores de 18años. Biociencias. 2016;11(1):41-47.

20. O Tabuenca R, Boente JL Lamas. Study of factors that influence theoutcome of ${ }^{131} \mathrm{I}$ treatment in hyperthyroidism secondary to nodular goitre. Rev Esp Med Nucl Imagen Mol. 2017;36(6):356-361.

21. MJ Azorín. Recombinant human thyrotropin stimulation prior to ${ }^{131} \mathrm{I}$ therapy in toxic multinodular Goitre with low radioactive iodine uptake. Revista Española Medicina Nuclear Imagen Mol. 2017;36(1):7-12.

22. N Gronich I, Lavi G Rennert, W Saliba. Cancer Risk After Radioactive Iodine Treatment for Hyperthyroidism: A Cohort Study. Thyroid Radiology and Nuclear Medicine. 2020;30(2):243-250.

23. B Torlinska, L Nichols, M Mohammed, et al. Patients Treated for Hyperthyroidism Are at Increased Risk of Becoming Obese: Findings from a Large Prospective Secondary Care Cohort. Thyroid. 2019;29(10):1380 1389.

24. Plazinska MT, Sawicka-Gutaj N, Czarnywojtek A, et al. Radioiodine therapy and Graves' disease - Myths andreality. PLoSOne. 2020;15(1).

25. YanD, ChenC, YanH, et al. Mortality Risk After Radio iodine Therapy for Hyperthyroidism: A Systematic Review and Meta-Analysis. EndocrPract. 2021;27(4):36-2369.

26. Azizi F, Malboosbaf R. Long-Term Antithyroid Drug Treatment: A Systematic Review and Meta-Analysis. Thyroid. 2017;27(10):1223-1231.

27. LM Martínez, P Velásquez, F Osorio, et al. Perfilclínicoy epidemiológico de pacient esaten didos porhipertiroidismoenel serviciode endocrinología deuna institución hospital ariade Medellín (Colombia) entre 2013 y 2015. .Archivosdemedicina. 2017;17(2).

28. Park S, Song E, Oh HS, et al. When should antithyroid drug therapy to reduce the relapse rate of hyperthyroidism in Graves' disease be discontinued. Endocrine. 2019;65(2):348-356.

29. A Hernández, I Hernández. La TSH recombinante humana. Qué tenemos,que esperamos y en quién la necesitamos. Rev Endocrinología y Nutrición. 2008;16(4):142-143.

30. Génesis. Cuidadosde Enfermería en pacientesconhi per tiroidismo Revista portales medicos. 2017.

31. Naupari ET. Cuidados de enfermería en pacientes postoperados de tiroidectomía en el servicio de cirugía de cabeza y cuello delhospital guillermo almenara irigoyen en el año 2016.Universidad AutónomadeI CA. 2016. 